NAMI die von uns präparativ durchgeführte $\mathrm{Ab}$ lösung der ribosomalen Ferritinfraktion, die nach den Gradientenbildern ${ }^{1}$ im Mittel mit $70 \mathrm{~S}$ sedimentiert, 10 Jahre früher erstmals im analytischen Maßstab gelungen ist.

Die für die Nucleoprotein-Komponente mit $49 \mathrm{~S}$ bestimmte Sedimentations-Konstante ${ }^{21}$ entspricht der Ferritin-freien größeren ribosomalen Untereinheit, von uns mit $47 \mathrm{~S}$ angegeben ${ }^{1}$, während die nach Ferritinablösung in kleinere Partikel von $8 \mathrm{~S}^{1}$ zerfallende kleine ribosomale Untereinheit von Takanami unbeachtet blieb, obwohl die Aufnahme seines Sedimentationslaufes ${ }^{21}$ deutlich eine startnahe, jedoch nicht ausgemessene Bande erkennen läßt.

Wir danken der Deutschen Forschungsgemeinschaft für Personal- und Sachbeihilfen sowie Fräulein B. Anton, Fräulein A. Hartmann und Fräulein U. Ross für ihre technische Mithilfe.

\title{
Potential Transducing Properties of Microelectrodes Filled with Electrolyte or Metal
}

\author{
C. C. Krischer and M. M. Deichmann \\ Institut für Zoologie der Technischen Hochschule Aachen \\ (Z. Naturforsch. 25 b, 72-80 [1970]; eingegangen am 29. Juli 1969)
}

\begin{abstract}
Glasmikropipetten mit Spitzendurchmessern von $2,5 \mu \mathrm{m}$, d. h. eine Größenordnung größer als die gewöhnlichen elektrophysiologischen Elektroden, werden dazu benutzt, in $0,1 \mathrm{M} \mathrm{KCl}$ die Potential-Übertragungseigenschaften (PTP) für Sinus- und Stufenpotential von Elektroden zu vergleichen, die gefüllt sind a) mit $0,1 \mathrm{M} \mathrm{KCl}(\mathrm{EM})$ und b) mit Metall (MM). Die PTP sind abhängig von drei Elektrodenparametern, $R_{\mathrm{S}}, R, C$ und von der Verstärkerstreukapazität $C_{\mathrm{a}}$. Die Parameter werden durch Messung des bei Anlegen einer Dreieckspannung entstehenden Strom-Zeitverlaufs bestimmt, Fig. 3. $R_{\mathrm{S}}$, der Lösungs-Serienwiderstand, ist vor der Elektrodenspitze lokalisiert, Fig. 1, table 1 . $R_{\mathrm{S}}$ bestimmt zusammen mit $C_{\mathrm{a}}$ die obere Grenzfrequenz der Messung, eqs. (11) und (12), Der Elektrodenwiderstand $R$ (table 2) und die Elektrodenkapazität $C$ sind bei EM kleiner als bei MM. Das führt - bei unkompensiertem $C_{\mathrm{a}}$ - zu komplementären PTP von EM und MM: EM sind besser für Niederfrequenzmessungen $(\omega R C \leqq 1$, d. h. $0-10 \mathrm{KHz}$ oder lange Stufendauer $t / R C \geqq 1$ ), während $\mathrm{MM}$ - wegen größerem $C$ - besser verwendbar sind zur Hochfrequenzmessung $(\omega R C \geqq 1, f \geqq 10 \mathrm{KHz}$ oder kurze Stufendauer $t / R C \leqq 1)$, Figs. 4 und 5 . Der Spannungsmeßverstärker, Fig. 2, gestattet elektronische Kompensation von $C_{\mathrm{a}}$. Die resulierende Verbesserung der PTP beträgt zwei Größenordnungen, Figs. 4, 5 und 6. MM mit Ag/AgCl- oder Sb-Füllung können zur Messung von $\mathrm{pCl}$ bzw. $\mathrm{pH}$ in anorganischen Elektrolyten verwendet werden, Fig. 7. Die unvermeidlichen Probleme von MM (sehr kritisch für MM kleiner als die Modellelektroden) werden im Appendix behandelt.
\end{abstract}

Of eminent importance for electrophysiology is the accurate measurement of $a c$ and dc membrane potential changes. For analytical purposes, the measurement of ion specific $\left(\mathrm{H}^{\oplus}, \mathrm{Na}^{\oplus}, \mathrm{Cl}^{\ominus}\right.$ etc. $)$ dc electrode potentials ${ }^{1}$ is needed. Hodgkin and HUXLEY $^{2}$ carried out the precise electrical characterization of the Loligo giant axon (diameter $\cong 1$ $\mathrm{mm})$. They showed that in this nerve potential changes occur which last only fractions of a millisecond. It is also known that cells smaller than the

1 P. C. Caldwell, J. Physiology 142, 22 [1958].

2 A. L. Hodkin and A. F. Huxley, J. Physiology 116, 449 [1952].

3 J. C. Eccles, The Physiology of Synapses, Springer-Verlag, Berlin-Göttingen-Heidelberg 1964.
Loligo axon undergo similar potential changes ${ }^{3}$. By using very small microelectrodes $(\leqq 0,5 \mu \mathrm{m}$ tips) for the investigation of such small cells one inevitably falsifies the result more than with measurements in a macroscopic scale. Attempts to control the disturbances by microelectrodes have been made by study. ing the electrical properties of two types of microelectrodes a) electrolyte and b) metal filled (Frank and Becker ${ }^{4}$ and LetTvin et al. ${ }^{5}$ ). The potential transducing properties of the two types of electrodes

4 K. Frank and M. Becker, Physical Techniques in Biological Research, Vol. V. Part A, Editor W. L. NAstuk, Academic Press, New York-London 1964.

5 R. C. Gesteland, B. Howland, J. Y. Lettrin, and W. H. PitTs, Proc. I.R.E. 47 (11), 1856 [1959]. 
are, however, difficult to compare because the investigated electrodes had different shapes and insulations.

This paper has the aim to present a manufacture of reproducible model electrodes which differ only in their electrolytic or metallic filling. The potential transducing properties are to be compared. With the results one should be able to extrapolate potential transducing properties of electrodes which differ in shape and nature from the used model electrodes.

\section{Characterization of electrode parameters}

The electrical analog for intracellular potential measurements with electrolyte filled micropipettes (EM) and metal filled micropipettes (MM) is seen in Fig. 1. The input impedance of the amplifier is represented by the resistance $R_{\mathrm{a}}$ and the capacitance $\mathrm{C}_{\mathrm{a}}$, respectively.

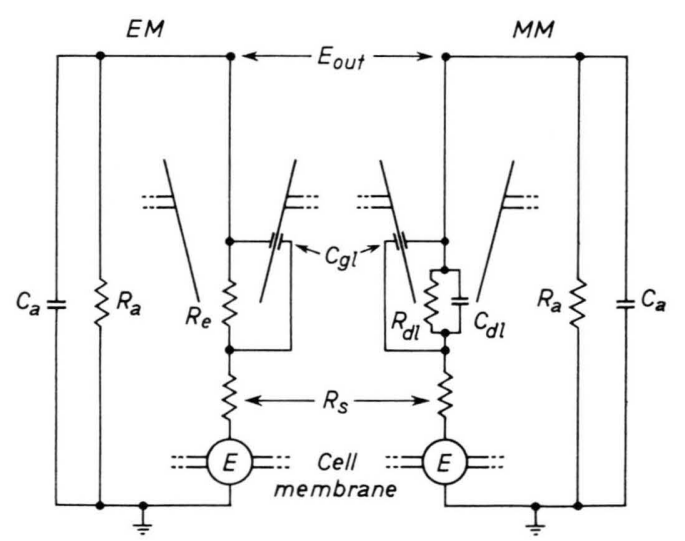

Fig. 1. Schematic drawing of an electrical equivalent circuit of micropipettes filled with electrolyte (EM) or metal (MM) which are impaled into a biological cell, symbolized by the dashed lines. The input impedance of the amplifier is represented by $R_{\mathrm{a}}$ and $C_{\mathrm{a}}$. The impedance of the counter electrode outside the cell is assumed to be zero and is therefore omitted in the figure. For further details see text.

The resistive components of the electrode impedance are for both types of electrodes represented by two resistances: a) $R_{\mathrm{s}}$ is located outside of the tip and is due to the concentration of electrical field lines in the immediate vicinity of the tip. For both types of electrodes $R_{\mathrm{S}}$ is assumed to be the same. Its value is obtained by integrating the resistance of a sphere of electrolyte with the resistivity $\varrho[\mathrm{Vcm} / \mathrm{A}]$

${ }^{6}$ C. C. Krischer, Z. Naturforschg. 24 b, 151 [1969].

7 Lavallée, Schanne, and Hébert, Glass Microelectrodes, J. Wiley \& Sons, New York-London-Sydney-Toronto 1969. of the surrounding fluid from the radius $r$ of the tip of the opening to $r=\infty$ :

$$
R_{\mathrm{S}}=\frac{\varrho}{4 \pi r s}[\mathrm{~V} / \mathrm{A}] \text {. }
$$

The factor $s$ corrects for the screening which is excerted by the glass insulation, $0<s<1$. b) The resistive components which are located within the tip. For $E M R_{\mathrm{e}}$ is calculated by integrating the resistance of a cone filled with an electrolyte of the resistivity $\varrho_{\mathrm{f}}$ from the radius $r$ of the opening to $r=\infty$.

$$
R_{\mathrm{e}}=\frac{\varrho_{\mathrm{f}}}{\pi r \operatorname{tg} \alpha}[\mathrm{V} / \mathrm{A}],
$$

where $\alpha$ is the angle between the axis and the mantle. Eq. (2) is only valid for electrodes with not too small tip diameters. Below a critical radius, which depends on the glass type and the electrolyte concentration the electrode rectifies and the electrode resistance becomes a function of the surface charge of the glass ${ }^{6,7}$.

The electrodes used in electrophysiological experiments are usually filled with $3 \mathrm{M} \mathrm{KCl}$. The specific resistivity of $3 \mathrm{M} \mathrm{KCl}$ can, however, not be used to calculate $R_{\mathrm{e}}$ since mixing of $3 \mathrm{M} \mathrm{KCl}$ and cell fluid takes place. If diffusion is rate controlling the initial transient mixing of electrolyte requires

$$
\tau_{\text {diff }} \approx \frac{r^{2}}{D}[\mathrm{sec}]^{8} .
$$

Where $D\left[\mathrm{~cm}^{2} / \mathrm{sec}\right]$ is the average diffusion constant. For the model electrodes $r=1,25 \mu \mathrm{m}$ and with the usual value of $D=10^{-5} \mathrm{~cm}^{2} / \mathrm{sec} \tau_{\text {diff }}$ is calculated to $1,5 \mathrm{msec} ;$ for the usual fine tips $(\phi \cong 0,2 \mu \mathrm{m}) \tau_{\text {diff }} \cong$ $10 \mu \mathrm{sec}$.

The order of magnitude of the contaminating steady state diffusion current $i_{0}$ can be estimated by using the following relation:

$$
i_{0}=\frac{\Phi}{R_{\mathrm{e}}}[\mathrm{A}],
$$

where $\Phi=R T / F[\mathrm{~V}]$ is the thermal voltage equivalent (at room temperature $=0,025 \mathrm{~V}$ ) with $R\left[\mathrm{VAsec} /{ }^{\circ} \mathrm{K}\right.$ equiv $]$ the gas constant, $T\left[{ }^{\circ} \mathrm{K}\right]$ the temperature, and $F\left[\right.$ Asec/equiv] the $\mathrm{F}$ a ra d a y constant. In eq. (4) $R_{\mathrm{e}}$ is the resistance of the electrode after allowance of equilibration (i.e. the tip is filled with a mixture of outside and inside electrolyte).

For $M M R_{\mathrm{dl}}$ is the resistance of the interphase metal-electrolyte. The value of $R_{\mathrm{dl}}$ is inversely proportional to the surface area. For a plain circular

8 J. C. Jaeger, Studies in Physiology, Editor: D. R. Curtis and A. K. MCINTYre, Springer-Verlag, Berlin-HeidelbergNew York 1965. 
surface

$$
R_{\mathrm{dl}}=\frac{R_{\mathrm{d} 1}^{*}}{\pi r^{2}}[\mathrm{~V} / \mathrm{A}],
$$

where $R \quad\left[\mathrm{Vcm}^{2} / \mathrm{A}\right]$ is the specific interphase resistance.

$R_{\mathrm{dl}}$ is the resistance equivalent of reversible or irreversible faradaic reactions which occur at the interphase metal-electrolyte. This reaction corresponds to the mixing in the tip of EM. Pioneering works in correlating the heterogeneous reaction kinetics with the electrical characteristics of electrodes are of WAGNER and Traud ${ }^{9}$, the B onhoeffer school (see VetTER ${ }^{10}$ ), DeLAHAY ${ }^{11}$ and others. For a reversible reaction the rate, resistance and concentration $c$ of reacting species, are correlated by the following expression ${ }^{10,11}$

$$
i_{0}=\frac{\Phi}{R_{\mathrm{dl}}}=\pi r^{2} \cdot k \cdot c \cdot F \quad[\mathrm{~A}]
$$

Many values for the rate constant $k[\mathrm{~cm} / \mathrm{sec}]$ or $i_{0} / \pi r^{2}$, the exchange current density ${ }^{10}$ can be obtained from electrochemical tables ${ }^{10,11}$. By inserting these values into eq. (6) one can calculate the interphase resistance or the flux.

The resistance $R_{\mathrm{dl}}$ is, however, not truely ohmic in character. For electrode polarizations exceeding $25 \mathrm{mV}$ $R_{\mathrm{dl}}$ usually changes. An exponential decrease of $R_{\mathrm{dl}}$ with increasing polarization is observed for reversible (and many irreversible) reactions ${ }^{10}$. For some electrodes such as Germanium ${ }^{12}$ or metals covered with insoluble oxides i. e. $\mathrm{Ta}^{13}$ or chlorides, $\mathrm{Ag} / \mathrm{AgCl}$ (own observations) $R_{\mathrm{dl}}$ increases with positive polarization and decreases on current reversal. Such rectifying current voltage relations are also typical for solid state $\mathrm{P}-\mathrm{N}$ junctions (diodes) ${ }^{14}$.

The ratio of the resistances of EM and MM with equal radii is with eqs. (2) and (5) given by:

$$
\frac{R_{\mathrm{e}}}{R_{\mathrm{dl}}}=\frac{\varrho \mathrm{f}}{{ }_{0} R_{\mathrm{d} 1}^{*} \operatorname{tg} \alpha} r \equiv \frac{r}{\varepsilon} .
$$

The constant $\varepsilon={ }_{0} R_{\mathrm{d} 1}^{*} \operatorname{tg} \alpha / \varrho_{\mathrm{f}}$ has the dimension of a length. If this length constant exceeds $r$ the resistance $R_{\mathrm{e}}$ is smaller than $R_{\mathrm{dl}}$. Inserting usual values of ${ }_{0} R_{\mathrm{dl}}^{*}, \varrho$ and $\operatorname{tg} \alpha$ in eq. (7) one obtains for $\varepsilon$ values between $5 \mu \mathrm{m}$ and $1 \mathrm{~cm}$.

The capacitive components $C$ of the electrode impedances arise at the phase boundaries which separate the conducting phases of the filling and the surrounding fluid. One capacity, $C_{\mathrm{gl}}$, fig. 1 , is due

9 C. W AGner and W. Traud, Z. Elektrochem. angew. physik. Chem. 44, 391 [1938].

10 K. J. Vetter, Elektrochemische Kinetik, Springer-Verlag, Berlin-Göttingen-Heidelberg 1961.

11 P. Delahay, New Instrumental Methods in Electrochemistry, Interscience, New York 1954

12 H. Gerischer, in: Advances in Electrochemistry and Electrochemical Engineering, P. Delahay, Interscience, New York 1962. to the glass mantle of the electrode. If differences in the fillings of EM and MM are neglected and if the thickness of the glass wall is assumed to increase linearly with increasing axial distance $l, C_{\mathrm{gl}}$ is for both types given by:

$$
C_{\mathrm{gl}}=C_{\mathrm{gl}}^{*} \cdot l[\text { Asec } / \mathrm{V}],
$$

where $C_{\mathrm{gl}}^{*}[\mathrm{Asec} / \mathrm{V} \mathrm{cm}]$ is a constant. Observed values for $C_{\mathrm{gl}}^{*}$ range between 4 and $10 \mathrm{pF} / \mathrm{cm}^{15,4}$.

MM have in parallel to $C_{\mathrm{gl}}$ the capacitor $C_{\mathrm{dl}}$ of the interphase metal-electrolyte, fig. 1 :

$$
C_{\mathrm{dl}}=C_{\mathrm{dl}}^{*} \cdot \pi \cdot r^{2} \quad[\mathrm{Asec} / \mathrm{V}],
$$

where $C_{\mathrm{d} l}^{*}\left[\mathrm{Asec} / \mathrm{Vcm}^{2}\right]$ is the double layer capacitor referred to unit area. In the region of small polarizations $C_{\mathrm{dl}}^{*}$ has a constant value of $20-100 \mu \mathrm{F} /$ $\mathrm{cm}^{2}{ }^{16,10}$. It is seen from eqs. (8) and (9) that MM have always a larger capacitor than EM. The ratio is:

$$
\frac{C(\mathrm{EM})}{C(\mathrm{MM})}=\frac{C_{\mathrm{gl}}}{C_{\mathrm{gl}}+C_{\mathrm{dl}}} .
$$

The potential transducing properties of EM and MM to sine wave potentials arising at $E$ in fig. 1 are described by:

$$
\frac{E_{\text {out }}}{E}=\sqrt{\frac{1+\omega^{2}(R C)^{2}}{\left(1-\omega^{2} R_{\mathrm{S}} C_{\mathrm{a}} R C\right)^{2}+\omega^{2}\left(R_{\mathrm{S}} C_{\mathrm{a}}+R C+R C_{\mathrm{a}}\right)^{2}}},
$$

where $\omega=2 \pi f ; f=$ frequency $(\mathrm{Hz}) ; R$ is $R_{\mathrm{e}}$ for EM and $R_{\mathrm{dl}}$ for MM; $C$ is $C_{\mathrm{gl}}$ for EM and $\left(C_{\mathrm{gl}}+\right.$ $\left.C_{\mathrm{dl}}\right)$ for MM. In the classical derivation of eq (11) is was assumed that the cell membrane is a potential source of zero internal impedance and $R_{\mathrm{a}} \gg R$ i. e. $R_{\mathrm{a}}$ was neglected.

For potential steps arising at $E$, fig. 1 the response is given by:

$$
\frac{E_{\text {out }}}{E}=1-\gamma \exp -\left(\frac{t}{\gamma R_{\mathrm{S}} C_{\mathrm{a}}}\right)+(\gamma-1) \exp -\frac{t}{R \Sigma C},
$$

where $\Sigma C=C_{\mathrm{gl}}+C_{\mathrm{a}}$ for EM and $\Sigma C=C_{\mathrm{gl}}+C_{\mathrm{dl}}+$ $C_{\mathrm{a}}$ for MM and $\gamma=C_{\mathrm{gl}} / \Sigma C$ for EM and $\gamma=\left(C_{\mathrm{gl}}+\right.$ $\left.C_{\mathrm{dl}}\right) / \Sigma C$ for MM.

13 A. Güntherschulze and H. Betz, Z. Elektroch. angew. physik. Chem. 37, 726 [1931].

14 W. Shockley, Electrons and Holes in Semiconductors, van Nostrand Co., New York 1950.

15 G. FAlK and P. Fatt, Proc. Roy. Soc. 160, 69 [1964].

16 D. C. Grahame, Chem. Rev. 41, 441 [1947]. 
Eq. (12) has been derived with the simplifying assumption that the time course of $E_{\text {out }}$ is determined by the sum of two exponentials, one containing the time constant $\gamma R_{\mathrm{s}} C_{\mathrm{a}}$ and reaching the potential level $E_{\text {out }} / E=\gamma$, and another exponential containing the time constant $R \cdot \Sigma C$ which leads to the final output potential $E_{\text {out }} / E=1$. $R_{\text {a }}$ was neglected.

Steady state $d c$ potentials of both types of electrodes have to be taken into account for $d c$ potential measurements. The fluxes of eqs. (4) and (6) cause for $E M$, eq. (4), a potential difference due to different concentrations and mobilities of the ions outside and in the interior of the electrode. In case of very narrow openings ${ }^{7}$ with rectifying properties ${ }^{6}$ the ionic double layer glass electrolyte can lead to ion specifity ${ }^{17}$. For MM, eq. (6), the flux at the interphase metal-electrolyte is potential determining (i. e. redox reactions). Coverings with sparely soluble chlorides or oxides may lead to ion specifity in regard to $\mathrm{Cl}^{\ominus}$ or $\mathrm{H}^{\oplus}$, respectively. For both, EM and MM, the potential usually is proportional to $n \Phi \log c$ where $c$ is the concentration of the potential determining ion and $n$ a factor which commonly has values between 0 and 2 .

\section{Methods}

Electrode preparation was done for EM and MM by breaking - prior to filling - the tips under the microscope to an outer diameter of $\cong 2,5 \mu \mathrm{m}$; EM were then filled by the action of capillary forces ${ }^{18}$ and $\mathrm{MM}$ by a method similar to the one described by LETTVIN ${ }^{5}$ : Molten woods metal was forced into the tip by the pressure of hot $\mathrm{CH}_{2} \mathrm{Cl}_{2}$ vapor which was sealed into the glass tube behind the zone of liquid metal. The metal in the outmost tip was then etched away chemically for a few $\mu \mathrm{m}$ and refilled electrolytically by silver or antimony. Care had to be taken not to exceed current densities of $20 \mathrm{~mA} / \mathrm{cm}^{2}$.

For the measurement of electrode parameters a triangle voltage which changes linearly with time was employed. For ohmic components (i. e. $R_{\mathrm{S}}$ and $R_{\mathrm{e}}$ ) the current $i$ is proportional to the potential, i.e. $(i)_{t}=$ $(E)_{t} / R$. For capacitive components (i. e. $C_{\mathrm{gl}}$ and $C_{\mathrm{gl}}+$ $\mathrm{C}_{\mathrm{dl}}$ ) the current $i_{\mathrm{c}}$ is proportional to the first derivative of the potential with respect to the time, i. e. $i_{\mathrm{c}}=$ $C_{\mathrm{gl}}(\mathrm{d} E / \mathrm{d} t)$. For details see fig. 3. To avoid $d c$ polarization of MM during the capacity measurements the triangle voltage was delivered via a $0,01 \mu \mathrm{F}$ condensor to an $\mathrm{Ag} / \mathrm{AgCl}$ wire as counter electrode. The latter was contained in a grounded metal box which had a

17 A. A. Lev, in: Glass Microelectrodes, Editors: LAvalléE, Schanne, and Hébert, John Wiley \& Sons, New York 1969.
$5 \mathrm{~mm}$ hole for the insertion of the microelectrode. This provision suppressed unwanted potential pickup. The $d c$ resistance of MM was measured by taking the slope of the $d c$ current voltage curves at small polarizations $(\leqq 25 \mathrm{mV})^{10}$. The current was measured with a current to voltage amplifier based on an operational amplifier $\mathrm{P} 25 \mathrm{~A}{ }^{18,19}$. In this current measurement no additional current monitoring resistor is introduced in series with the electrode resistance.

The potential transducing properties of EM and MM were measured with an operational amplifier in the configuration shown in fig. 2. $C_{\mathrm{f}}$ serves to compensate the stray capacity $C_{\mathrm{a}}$ at the input, fig. $1 . C_{\mathrm{a}}$ is compensated if $(A-1) C_{\mathrm{f}}=C_{\mathrm{a}}$ where $A$ is the gain of the amplifier ${ }^{4}$. In fig. 2 the gain $A=1,5$. For most ac measurements a commercial amplifier Philbrick type P25A ${ }^{19}$ was employed. Its approximate input characteristics are: $R_{\mathrm{a}}=10^{11} \mathrm{Ohm}, C_{\mathrm{a}}=8 \mathrm{pF}$ and the offset current $i_{\text {off }}=10^{-11} \mathrm{~A}$. For dc measurements with MM a Philbrick module P2AU with offset current $\leqq 10^{-12} \mathrm{~A}$ was employed.

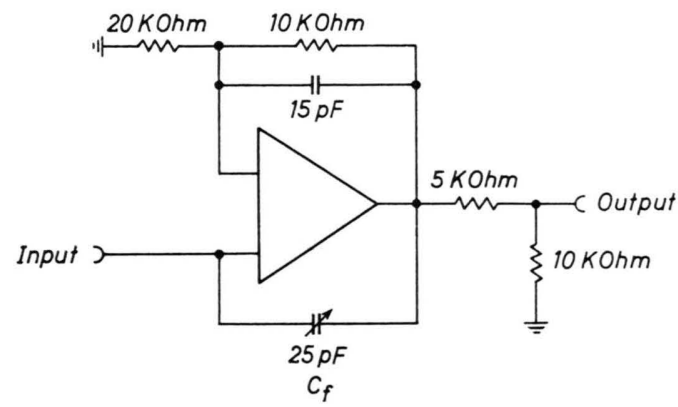

Fig. 2. Circuit diagram of a potential measuring amplifier with provision for the compensation of stray capacity. The operational amplifier (triangle) was a PHILBRICK ${ }^{19}$ model $\mathrm{P} 25 \mathrm{~A}$ or P2AU. The trim condensor $C_{\mathrm{f}}$ serves to compensate the stray capacity.

\section{Results}

Fig. 3 demonstrates how electrode parameters can be obtained from a current pattern which results when EM of tip diameter $\cong 2,5 \mu \mathrm{m}$ is subjected to a triangle voltage clamp. For better comparison the negative current peaks are taken as reference current and labelled zero. It is seen that the different penetration of the electrode into the agar gel mainly yields a change of the capacitive current level $i_{\mathrm{c}}$. The straight portions of the curves which are due to the resistive components of the electrode are relatively independent of the immersion as it is expected

18 C. C. Krischer, Z. Naturforschg. 24 b, 156 [1969].

19 Philbrick, Applications Manual, Philbrick Researches Inc., Nimrod Press, Boston 1966. 


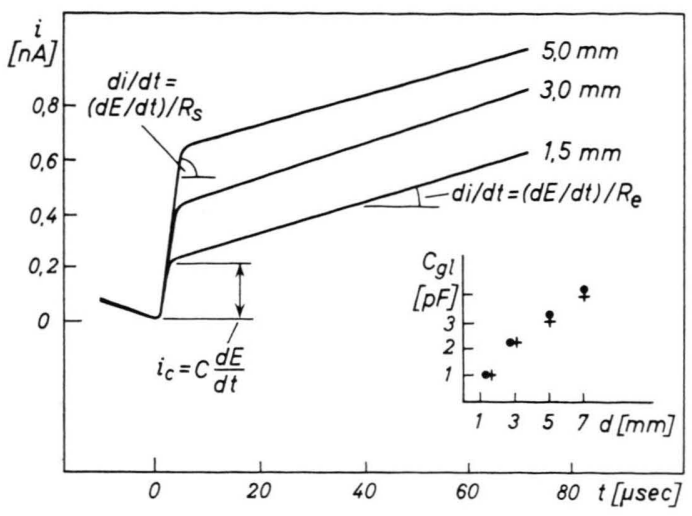

Fig. 3. Current flow obtained by applying a triangle voltage to EM of tip diameter $\cong 2,5 \mu \mathrm{m}$. Depth of immersion into $1 \%$ agar gel in $0,1 \mathrm{~m} \mathrm{KCl}$ is indicated at each curve. $\mathrm{d} E / \mathrm{d} t$ of the input signal was $\pm 185 \mathrm{~V} / \mathrm{sec}$. $\mathrm{EM}$ is filled with $0,1 \mathrm{M} \mathrm{KCl}$. The current was measured with an operational amplifier type P25A ${ }^{19}$ with $1 \mathrm{MOhm}$ as feedback resistor. The values are: $R_{\mathrm{s}}=700 \mathrm{KOhm}, R_{\mathrm{e}}=10 \mathrm{MOhm}$. Inlet: Values of two measurements of $C_{\mathrm{gl}}$ as a function of the depth of immersion. The slope of the curve corresponds to the parameter $C_{\mathrm{g} 1}^{*}$.

theoretically. The resistances evaluated from the slopes of the straight portions are $R_{\mathrm{s}}=700 \mathrm{KOhm}$ and $R_{\mathrm{e}}=10 \mathrm{MOhm}$.

Table 1 contains a collection of measurements of $R_{\mathrm{s}}$, the resistance of the solution in front of the tip.

\begin{tabular}{ccccc}
\hline $\begin{array}{c}\text { electrode } \\
\text { type }\end{array}$ & $\begin{array}{c}\varnothing \mathrm{tip} \\
\mu \mathrm{m}\end{array}$ & filling & $\begin{array}{c}R_{\mathrm{S}} \\
{[\mathrm{MOhm}]}\end{array}$ & $\begin{array}{c}\text { total } \\
\text { number } \\
\text { of elec- } \\
\text { trodes }\end{array}$ \\
\hline EM & 2,5 & $0,1 \mathrm{MKCl}$ & $0,85 \pm 0,1$ & 5 \\
EM & 0,2 & $0,1 \mathrm{MKCl}$ & $4,80 \pm 1,4$ & 5 \\
MM & 2,5 & $\mathrm{Ag} / \mathrm{AgCl}$ & $0,22 \pm 0,045$ & 12 \\
\hline
\end{tabular}

Table 1. Series Solution Resistances.

The measurement of the electrode resistance (i.e. within the tip) yielded the values shown in table 2 .

\begin{tabular}{ccccrc}
\hline $\begin{array}{c}\text { elec- } \\
\text { trode } \\
\text { type }\end{array}$ & $\varnothing \mathrm{m}$ tip & filling & $\begin{array}{c}\text { sur- } \\
\text { rounding } \\
\text { solution }\end{array}$ & $\begin{array}{r}R_{\mathrm{e}} \text { or } R_{\mathrm{dl}} \\
{[\mathrm{MOhm}]}\end{array}$ & $\begin{array}{c}\text { total } \\
\text { number } \\
\text { of elec- } \\
\text { trodes }\end{array}$ \\
\hline $\mathrm{EM}$ & 0,2 & $0,1 \mathrm{MKCl}$ & $0,1 \mathrm{MKCl}$ & $50,6 \pm 14,6$ & 5 \\
$\mathrm{EM}$ & 2,5 & $0,1 \mathrm{MKCl}$ & $0,1 \mathrm{MKCl}$ & $9,4 \pm 0,1$ & 5 \\
$\mathrm{MM}$ & 2,5 & $\mathrm{Ag}$ & $0,1 \mathrm{MKCl}$ & $280,0 \pm 54,0$ & 6 \\
$\mathrm{MM}$ & 2,5 & $\mathrm{Ag} / \mathrm{AgCl}$ & $0,1 \mathrm{MKCl}$ & $45,0 \pm 3,0$ & 4 \\
$\mathrm{MM}$ & 2,5 & $\mathrm{Sb}$ & $0,1 \mathrm{MKCl}$ & $83,0 \pm 16,0$ & 3 \\
\hline
\end{tabular}

Table 2. Electrode Resistances.

The resistances of table 2 were only for EM independent of polarization up to $50 \mathrm{~mA} / \mathrm{cm}^{2}$. For MM in $0,1 \mathrm{M}$ $\mathrm{KCl}$ the resistance of polarized electrodes, $R$, differed from the resistance of unpolarized electrodes, $R_{0}$. The bare $\mathrm{Ag}$ electrodes had the resting potential at
$-400 \mathrm{mV}$ vs saturated calomel electrode (S.C.E.). At cathodic current densities of $5 \mathrm{~mA} / \mathrm{cm}^{2}(E=-550 \mathrm{mV})$ $R$ was $0,7 \cdot R_{0}$, whereas at $5 \mathrm{~mA} / \mathrm{cm}^{2}$ anodic polarization $R$ was $6,5 \cdot R_{0}$ at $0 \mathrm{mV}$ vs S.C.E. The antimony electrode had the resting potential at $-300 \mathrm{mV}$ vs S.C.E. The current increased in the cathodic and anodic direction exponentially with increasing polarization. At cathodic current densities of $50 \mathrm{~mA} / \mathrm{cm}^{2}(E=-600 \mathrm{mV}) R$ was $0,25 \cdot R_{0}$, at $50 \mathrm{~mA} / \mathrm{cm}^{2}$ anodic polarization $(E=0 \mathrm{~V})$ $R$ was $0,40 \cdot R_{0}$ vs S.C.E. $\mathrm{Ag} / \mathrm{AgCl}$ electrodes were obtained by anodic charging of $\mathrm{Ag}$ with $\cong 5 \cdot 10^{-10}$ Asec. The resting potential was at $+50 \mathrm{mV}$ vs S.C.E. The resistance of polarized electrodes differed from the resistance of the unpolarized electrodes. In the cathodic direction it was $0,7 \cdot R_{0}$ and in the anodic direction it was $1,2 \cdot R_{0}$.

The capacitive components of the electrode impedance were obtained as described in connection with Fig. 3. For EM the slope of the curve in the inset $\mathrm{d} C_{\mathrm{gl}} / \mathrm{d}(d)$ is the parameter $C_{\mathrm{gl}}^{*}$. At small penetrations of the electrode into the agar gel $C_{\mathrm{vl}}^{*}=0,7 \mathrm{pF} /$ mm. 12 other EM yielded for $C_{\mathrm{gl}}^{*} 0,8 \pm 0,1 \mathrm{pF} / \mathrm{mm}$.

For $M M(\mathrm{Ag} / \mathrm{AgCl})$ the electrode capacity $C=$ $C_{\mathrm{gl}}+C_{\mathrm{dl}}$ was $18,6 \pm 2,1 \mathrm{pF}$ (12 measurements) for $\mathrm{d} E / \mathrm{d} t=50 \mathrm{~V} / \mathrm{sec}$. Test measurements at $\mathrm{d} E / \mathrm{d} t=$ $5 \mathrm{~V} / \mathrm{sec}$ and $500 \mathrm{~V} / \mathrm{sec}$ yielded values of $C$ which differed not more than $15 \%$ from this value.

The ac potential transducing properties of EM and MM for sine wave of $20 \mathrm{mV}$ amplitude (peak to peak) are shown in fig. 4 . It is seen that for uncompensated $C_{a}$ (curves to the left) the output potential begins to decrease for MM at lower frequencies

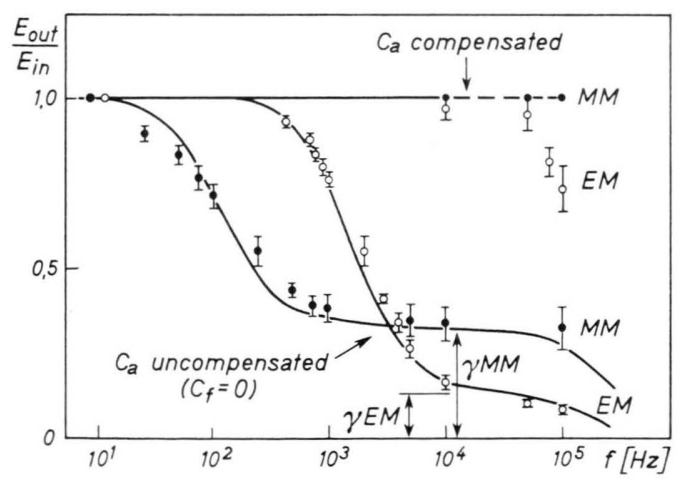

Fig. 4. Sine wave frequency response of microelectrodes of a tip diameter of $\cong 2,5 \mu \mathrm{m}$, dipping $1,5 \mathrm{~mm}$ into $1 \%$ agar gel in $0,1 \mathrm{M} \mathrm{KCl}$. Each bar represents the standard deviation of measurements obtained with three different electrodes. The sine wave $(20 \mathrm{mV}$ peak to peak) was applied via an $\mathrm{Ag} / \mathrm{AgCl}$ wire to the microelectrode. The potential measuring circuit of fig. 2 containing a Philbrick P25A amplifier was used. The curves are calculated with eq. (11). The assumed parameters were: $\mathrm{MM}, \mathrm{Ag} / \mathrm{AgCl}$ filling: $C_{\mathrm{a}}=16 \mathrm{pF}, C=8 \mathrm{pF}, R_{\mathrm{s}}=$ $0,2 \mathrm{MOhm}, R_{\mathrm{dl}}=70 \mathrm{MOhm}$. EM, $0,1 \mathrm{M} \mathrm{KCl}$ filling: $C_{\mathrm{a}}=$ $12 \mathrm{pF}, C=2 \mathrm{pF}, R_{\mathrm{S}}=1,0 \mathrm{MOhm}, R_{\mathrm{dl}}=10 \mathrm{MOhm}$. 
than for EM. MM maintain, however, at higher frequencies a higher level of the output potential. For optimally compensated stray capacity (upper curves) MM maintain full amplitude up to $100 \mathrm{KHz}$ whereas for EM $E_{\text {out }}$ has dropped at $100 \mathrm{KHz}$ to $70 \%$ of the input potential.

The response curves of EM and MM to applied step potentials of $20 \mathrm{mV}$ amplitude are shown in fig. 5. $C_{\mathrm{f}}$, fig. 2 , was zero. Analogous to the response to sine wave MM have lower amplitude than EM at long durations whereas for short durations the reverse is true: $E_{\text {out }}(\mathrm{MM})>E_{\text {out }}(\mathrm{EM})$. The mentioned potential levels $\gamma=C / C+C_{\mathrm{a}}$ are marked by double arrows in figs. 4 and 5 .

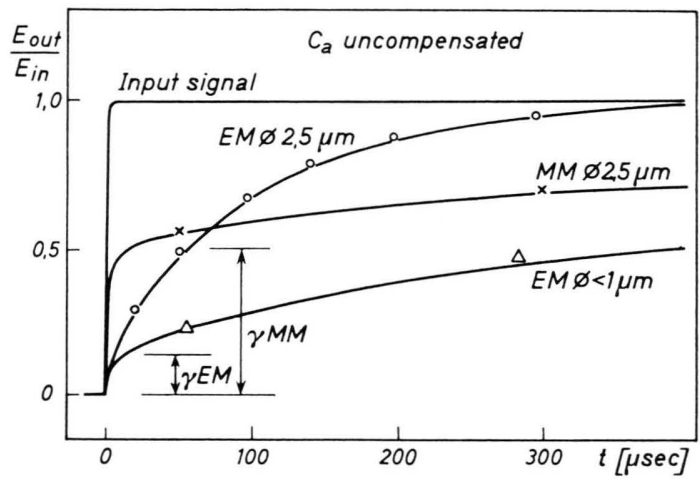

Fig. 5. Response of microelectrodes to applied potential steps of $20 \mathrm{mV}$ amplitude. The measurements were carried out as indicated in fig. 4 . $C_{\mathrm{f}}$ of fig. 2 was zero. The markings $\times, \mathrm{O}$, $\triangle$ are values calculated with eq. (12). The chosen parameters were: $\mathrm{EM}, 0,1 \mathrm{M} \mathrm{KCl}$ filling, $\phi 2,5 \mu \mathrm{m}: C_{\mathrm{a}}=12 \mathrm{pF}, C=$ $2 \mathrm{pF}, R_{\mathrm{e}}=7 \mathrm{MOhm}, \mathrm{EM}, 0,1 \mathrm{M} \mathrm{KCl}$ filling, $\phi \leqq 1,0 \mu \mathrm{m}$ : $C_{\mathrm{a}}=12 \mathrm{pF}, C=2 \mathrm{pF}, R_{\mathrm{e}}=40 \mathrm{MOhm}, \mathrm{MM}, \mathrm{Ag} / \mathrm{AgCl}$ filling, $\phi 2,5 \mu \mathrm{m}: C_{\mathrm{a}}=12 \mathrm{pF}, C=12 \mathrm{pF}, R_{\mathrm{dl}}=25 \mathrm{MOhm}$, $R_{\mathrm{S}}$ for all electrodes $=1 \mathrm{MOhm}$.

The effect of electronic compensation of $C_{\mathrm{a}}$, fig. 1 , via $C_{\mathrm{f}}$, fig. 2 , on the potential transduction of step functions is demonstrated in fig. 6. The response of MM closely resembles the input signal. The delay of $2 \mu$ sec could be reduced to $1 \mu$ sec by using an especially wideband amplifier, Philbrick, type $\mathrm{P} 25 \mathrm{AH}^{19}$. EM of tip diameter $\cong 2,5 \mu \mathrm{m}$ are seen to have a much slower rise to the final potential level $E_{\text {out }} / E=1$. For the included curve of EM with the usual fine tip of diameter $\leqq 0,5 \mu \mathrm{m}$ the final potential level could not be reached in the first $15 \mu$ sec because the amplifier began to oscillate in the used configuration if $C_{\mathrm{f}}$ was increased more.

Measurements of dc potentials of $M M$ reported in fig. 7. It is seen that MM filled with $\mathrm{Sb}$ or $\mathrm{Ag} / \mathrm{AgCl}$ have ion specific potentials depending on $\mathrm{pH}$ or $\mathrm{pCl}$,

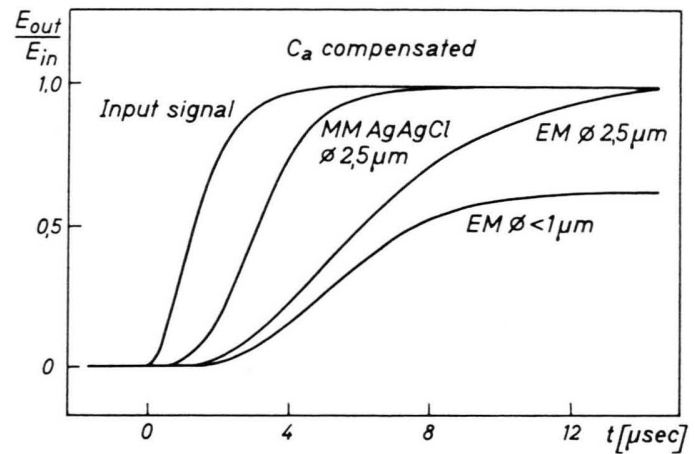

Fig. 6. Response of microelectrodes to applied potential steps of $20 \mathrm{mV}$ amplitude. Same electrodes and measuring conditions as in fig. 5 with the exception that $C_{\mathrm{f}}$ (see fig. 2) was for each electrode adjusted to yield optimal response. The response of the measurement with the fine electrode $(\phi \leqq$ $1 \mu \mathrm{m})$ could not be improved because of the onset of oscillations.

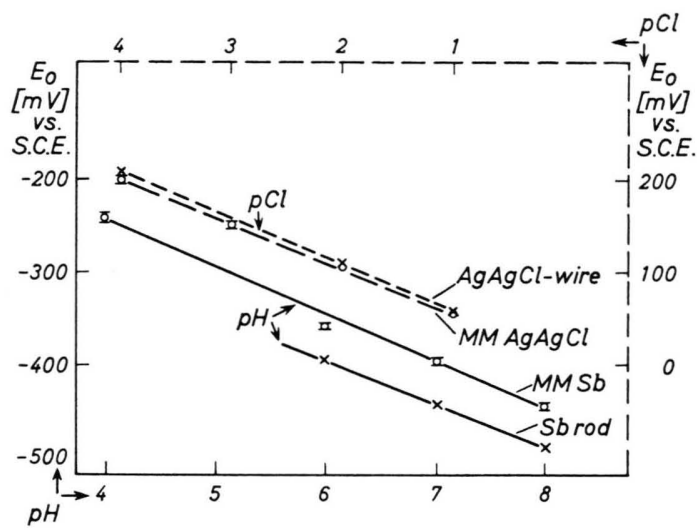

Fig. 7. Potential $E_{0}$ measured versus saturated calomel electrode (S.C.E.) of three different metal microelectrodes (tip diameter $\cong 2,5 \mu \mathrm{m}$ ) as a function of the logarithm of ion concentration (the bars represent the standard deviation). Upper curves: a) $\mathrm{Ag} / \mathrm{AgCl}$ microelectrodes in $0,1 \mathrm{M} \mathrm{KCl} /$ $\mathrm{KNO}_{3}$ mixtures of varying $\mathrm{Cl}^{\ominus}$ content. b) $\mathrm{Ag} / \mathrm{AgCl}$-wire in the same mixtures. Lower curves: $\mathrm{Sb}$ microelectrode and $\mathrm{Sb}$ $\operatorname{rod}(0,5 \times 1,0 \mathrm{~cm})$, respectively, in universal buffer $(0,1 \mathrm{M}$ $\left.\mathrm{H}_{3} \mathrm{BO}_{3} \mathrm{H}_{3} \mathrm{PO}_{4} \mathrm{CH}_{3} \mathrm{CO}_{2} \mathrm{H}+\mathrm{KOH}\right)$ of varying $\mathrm{pH}$. The measuring amplifier was Philbrick P2AU in the configuration of fig. 2. Prior to the measurement the offset trim was adjusted to have an offset current $\cong 0,2 \mathrm{pA}$ (measured with a resistor of $500 \mathrm{MOhm})$. Note: the scales to the two curves at the top are at the right side, the scales to the bottom curves are at the left side.

respectively. The curves measured at $\mathrm{MM}$ and at the corresponding macroscopic electrodes are parallel. With a pretreatment of the $\mathrm{Sb}$ rod by concentrated $\mathrm{HNO}_{3}$ the curve could be shifted $100 \mathrm{mV}$ towards positive potentials. The use of the amplifier with offset current $\leqq 1 \mathrm{pA}$ was especially needed for MM filled with $\mathrm{Sb}$. Larger offset currents sometimes 
destroyed the electrode quickly by anodic dissolution. At $\mathrm{Ag} / \mathrm{AgCl}$ electrodes anodic offset currents increased the resistance and decreased the capacity but the steady state potential remained unaffected.

\section{Discussion}

The experiments showed that the measurement of all microelectrode parameters is possible by employing a linearly changing voltage. A simple current to voltage converter based on operational amplifiers serves as a convenient current measuring device ${ }^{18}$. The series solution resistance - which is responsible for the high frequency limit of recording, see below - was characterized as being located in front of the tip, fig. 1. Because the pipettes and the electrolyte of EM and MM were identical, the $R_{\mathrm{s}}$ values should have been the same. Table 1 shows, however, that $R_{\mathrm{s}}(\mathrm{EM})$ is $\cong 4 \cdot R_{\mathrm{s}}$ (MM). This discrepancy can be explained by assuming that for EM part of $R_{\mathrm{e}}$ has to be included into $R_{\mathrm{s}}$; the capacity of the glass wall, $C_{\mathrm{gl}}$, shunts $R_{\mathrm{e}}$ incompletely. The shunt of the electrode resistance $R_{\mathrm{dl}}$ by $\mathrm{C}_{\mathrm{dl}}$ is evidently perfect for MM.

If an estimate of $R_{\mathrm{s}}$ is required (for high frequency measurements, see below) the approximation $R_{\mathrm{s}}(\mathrm{EM}) \cong 0.1 \cdot R_{\mathrm{e}}$ can be used. This means that in eq. (1) $s$ has to be taken 0,25 [if $\alpha=6^{\circ}$, eq. (2)]. For MM the estimate $R_{\mathrm{s}} \cong 0,025 \cdot R_{\mathrm{e}}$ would be adequate $\left(R_{\mathrm{e}}\right.$ is the $d c$ resistance of a micropipette which has the same radius as the metal electrode and which is filled with the liquid that surrounds the metal electrode).

The electrode resistances $R$, (i. e. $R_{\mathrm{e}}$ and $R_{\mathrm{dl}}$ ) were for EM smaller than for MM. From table 2 one obtains for $R_{\mathrm{e}} / R_{\mathrm{dl}} 0,034 ; 0,21 ; 0,11$ for $\mathrm{Ag}, \mathrm{Ag} / \mathrm{AgCl}$, and $\mathrm{Sb}$, respectively. With eq. (7) one calculates for the constant $\varepsilon[\mu \mathrm{m}]$ the values of $36 \mu \mathrm{m}, 5,6 \mu \mathrm{m}$, $11 \mu \mathrm{m}$ for $\mathrm{Ag}, \mathrm{Ag} / \mathrm{AgCl}$ and $\mathrm{Sb}$, respectively. Metal electrodes with such radii would have identical resistances as EM of the same radius.

The steady state flux of ions diffusing through the tip of EM is, with eq. (4), calculated $0,27 \mathrm{nA}$ or $i_{0} / F=2,8 \cdot 10^{-14} \mathrm{eq} / \mathrm{sec}$ in fair agreement with a measured value of $6 \cdot 10^{-14} \mathrm{eq} / \mathrm{sec}$ for a $0,5 \mu \mathrm{m}$ tip, $3 \mathrm{M} \mathrm{KCl}$, quoted in reference ${ }^{20}$. The corresponding corrosion fluxes of MM are much smaller, i. e.

20 Bures, Petran, and Zachar, Electrophysiological Methods in Biological Research, Academic Press, New YorkLondon 1967.
$0,09 \mathrm{nA}, 0,056 \mathrm{nA}, 0,029 \mathrm{nA}$ or $i_{0} / F=0,094 \cdot 10^{-14}$ $\mathrm{eq} / \mathrm{sec}, \quad 0,058 \cdot 10^{-14} \mathrm{eq} / \mathrm{sec}, \quad 0,031 \cdot 10^{-14} \mathrm{eq} / \mathrm{sec}$, for $\mathrm{Ag}, \mathrm{Ag} / \mathrm{AgCl}$, and $\mathrm{Sb}$, respectively. It has, however, to be remembered that the corrosion products might be poisonous to biological cells.

For the capacitive components $C$ of the electrode impedance, eqs. (8) and (9), the agreement of derived and measured values is satisfactory: For $E M C=C_{\mathrm{gl}}$ depends on the length of the wetted part of the electrode, eq. (8), fig. 3. $C_{\mathrm{gl}}^{*}$ was found in the same order of magnitude as the values which were reported by other authors ${ }^{4,15}$. In intracellular measurements $C_{\mathrm{gl}}$ is divided by the membrane into one part inside the cell and another part outside. The latter contribution of $C_{\mathrm{gl}}$ has to be considered as stray capacity and becomes part of $C_{\mathrm{a}}$.

The capacity of $M M$ is mainly the double layer capacity of the interphase metal-electrolyte. Insertion of the common value $C_{\mathrm{dl}}^{*} \cong 100 \mu \mathrm{F} / \mathrm{cm}^{2}$ into eq. (9) yields for MM (1,5 mm immersion) a capacity of $\cong 12 \mathrm{pF}$ in fair agreement with the measurements.

The electrode capacitances of the used model electrodes are therefore with 2 to $20 \mathrm{pF}$ in the same order of magnitude as the specified input capacitors of usual amplifiers.

The discussion of the ac potential transducing properties of $E M$ and $M M$ can be restricted to the more familiar sine wave because this wave form and step function are correlated via Fourier transform. For most experiments step functions are to be preferred because a single step response - appropriately displayed - contains the required information. The discussion therefore includes in brackets step durations which correspond to certain frequency ranges.

The response curves of EM and MM with uncompensated stray capacity (i. e. $C_{\mathrm{a}}$ of similar size as $C$ ) are mainly determined by two time constants, $R \cdot C$ $=\tau$ (i. e. electrode resistance times electrode capacitance) and $R_{\mathrm{s}} \cdot C_{\mathrm{a}}=\tau_{\mathrm{s}}$ (i. e. series solution resistance times stray capacity), see eqs. (11) and (12). Two different frequency ranges (step durations) of the response curves can be distinguished:

1. at low frequencies (long step durations $t$ ) i.e. $\omega \cong 1 / \tau(t \cong \tau)$ the terms $\omega \tau(t / \tau)$ and $\omega R \Sigma C$ are, in eq. (11), responsible for the decrease of $E_{\text {out }} / E$ with increasing frequency (decreasing step duration). The terms containing $R_{\mathrm{s}}$ in eqs. (11) and (12) can be neglected. It is seen in fig. 4 (5) that for the used model electrodes this frequency is near 
$100 \mathrm{~Hz}$ (1 msec) for MM and near $1 \mathrm{KHz}(100$ $\mu \mathrm{sec}$ ) for EM, respectively.

2. at high frequencies (short step durations) i. e. $\omega \cong 1 / \tau_{\mathrm{s}}$ the term $\omega \tau_{\mathrm{s}}$ in eq. (11), [t/ $\tau_{\mathrm{s}}$, eq. (12)], predominates the frequency response. The terms containing $R$ can be neglected and $E_{\text {out }} / E$ approaches zero with $1 / \omega \tau_{\mathrm{s}}\left(1-\exp -t / \tau_{\mathrm{s}}\right)$. The curves in fig. 4 indicate that this frequency is near $100 \mathrm{KHz}$ for EM and near $400 \mathrm{KHz}$ for MM. The measured values do, however, not extend far enough into this frequency range.

The capacitive parameters $\gamma=C / C+C_{\mathrm{a}}$ determine the magnitude of $E_{\text {out }}$ in the frequency range (time span) in between the frequency ranges which were discussed above. for $1 / \tau<\omega<1 / \tau_{\mathrm{s}} \quad\left(\tau_{\mathrm{s}}<t<\tau\right)$ $E_{\text {out }} / E$ is close to the potential level $\gamma$, eq. (12), figs. 4 and 5 . It is seen in fig. 4 (5) that due to $C(\mathrm{MM})>C(\mathrm{EM})$ metal electrodes have $E_{\text {out }} / E=$ $\gamma(\mathrm{MM})=0,33(0,5)$ whereas EM have $\gamma(\mathrm{EM})=$ $0,14(0,14)$. The bandwidth (time span) of this potential level is (for similar values of $C$ and $C_{\mathrm{a}}$ ) given by the values of $R$ and $R_{\mathrm{s}}$. For EM $R / R_{\mathrm{s}}$ was $\cong 10$ whereas for $\mathrm{MM} R / R_{\mathrm{s}}$ was $\cong 300$. It can be extrapolated in fig. 4 that the bandwidth of $\gamma$ is for EM indeed much smaller than for MM. The small divergence of the parameters used to compute the curves and the ones reported in the tables is probably due to polarization by offset currents. It was impossible to avoid this polarization because the wideband measurements excluded ac coupling.

The effect of electronic compensation of $C_{\mathrm{a}}$ is a reduction of the effective value of $C_{\mathrm{a}} ; \gamma$ in eq. (12) approaches one. In eqs. (11), [(12)] $E_{\text {out }} / E=1$ for low frequency (long step duration). At high frequency (short step duration) $E_{\text {out }} / E_{\text {in }}$ decreases (increases) with $1 / \omega R_{\mathrm{s}} C_{\mathrm{a}}\left(1-\exp -t / R_{\mathrm{s}} C_{\mathrm{a}}\right)$, where $C_{\mathrm{a}}$ is the remaining rest of stray capacity. The improvement of the response curves by the neutralization of $C_{\mathrm{a}}$ is evident in fig. 4: For EM the recorded $E_{\text {out }}$ is at $\cong 20 \mathrm{KHz} 80 \%$ of $E$ whereas $\mathrm{MM}$ record the full signal up to $100 \mathrm{KHz}$. This superiority of MM for recording is seen in more detail in fig. 6 : EM with tip diameter $\cong 2,5 \mu$ m reach $70 \%$ of the final amplitude in $\cong 10 \mu$ sec. For MM the recorded signal is - apart from the mentioned $2 \mu$ sec delay practically identical with the input signal.

21 I. Levin, Chemist-Analyst 41, 89 [1952].

22 G. Küchler, H. Beyer, M. Himmel, and B. Merrem, Pflügers Arch. ges. Physiol. Menschen Tiere 280, 210 [1964].
The $d c$ potential measurements of $M M$ filled with $\mathrm{Ag} / \mathrm{AgCl}$ and $\mathrm{Sb}$, fig. 7, show that these MM had for more than three decades of concentration in the used inorganic electrolytes $d c$ potentials proportional to $\mathrm{pCl}$ and $\mathrm{pH}$. The constant of proportionality is with $50 \mathrm{mV} /$ decade for $\mathrm{Sb}$ and $48 \mathrm{mV} /$ decade for $\mathrm{Ag} / \mathrm{AgCl}$ fairly close to the theoretical value of $58 \mathrm{mV} /$ decade of the $\mathrm{Nernst}$ equation for monovalent reactions. The curves measured at $\mathrm{Sb}$ are in accord with measurements at somewhat larger Sbmicroelectrodes ${ }^{21}$.

Under the conditions of the reported experiments EM have no $d c$ potential drop across the opening. For different electrolytes inside and outside of the tip other investigators have observed the expected relationship: $E=E_{0} \pm b \log c$, with $b$ a constant usually smaller than $58 \mathrm{mV} /$ decade $^{17,22,23,7}$.

\section{Appendix}

The results of this paper allow a crude estimate of the potential transducing properties $(P T P)$ of microelectrodes which have smaller tips than the model electrodes.

For the usual fine tipped micropipettes, $\mathrm{EM}_{\mathrm{f}}$, (tip diameter $\leqq 0,5 \mu \mathrm{m})$ filled with $3 \mathrm{M} \mathrm{KCl}$ and impaled $150 \mu \mathrm{m}$ into a biological cell the electrode resistance $R$ is probably one order of magnitude larger than the resistance of the model electrode, $\mathrm{EM}_{\mathrm{m}}$, (tip diameter $2,5 \mu \mathrm{m}) 0,1 \mathrm{M} \mathrm{KCl}$ filling. The recording electrode capacity is much smaller, i. e. $C\left(\mathrm{EM}_{\mathrm{f}}\right) \cong 0,1 \cdot C\left(\mathrm{EM}_{\mathrm{m}}\right)$. The upper frequency limit $f_{\text {lim }}$ for recording with an amplifier like the one in fig. 2 is with these $\mathrm{EM}_{\mathrm{f}}$ parameters at least one order of magnitude lower than for $\mathrm{EM}_{\mathrm{m}}$; $f_{\text {lim }}=1 \mathrm{KHz}$ is an optimistic estimate.

If appropriate MM were used for intracellular recording the frequency limit could be extended. The extrapolation of MM electrode parameters to a tip diameter $\cong 1 \mu \mathrm{m}$ may be taken as exemple for MM with very small tips. For $\mathrm{Ag} / \mathrm{AgCl}$ the parameters are estimated as follows:

$R_{\mathrm{S}} \quad($ extrapolated for $200 \mathrm{Ohmcm}$ cytoplasma $) \cong$ 1 MOhm,

$R_{\mathrm{dl}} \quad($ extrapolated in $0,1 \mathrm{M} \mathrm{KCl}) \cong 500 \mathrm{MOhm}$,

$C_{\mathrm{dl}} \quad($ extrapolated in $0,1 \mathrm{M} \mathrm{KCl}) \cong 1 \mathrm{pF}$.

A crude extrapolation of the upper frequency limit $f_{\text {lim }}$ of recording with compensated $C_{\mathrm{a}}$ is $f_{\text {lim }}=20 \mathrm{KHz}$ (like the upper curve "EM" in fig. 4) .

It has to be pointed out that such small MM are extremely sensitive to offset currents or transient charging. The electrochemical formation of a monolayer of sparely soluble substances such as $\mathrm{AgCl}$ would re-

${ }^{23}$ H. KRUEGer, Elektrochemische Eigenschaften von Kapillarmikroelektroden, Diplomarbeit, Universität München 1963. 
quire the charge $q=p \cdot e_{0} \cdot f \cong 1,6 \cdot 10^{-12}$ Asec, where: $p=10^{15}$ Atoms $/ \mathrm{cm}^{2}$, the population of atoms on one square centimeter of surface, $e_{0}=1,6 \cdot 10^{-19}$ Asec/atom, the elementary charge and $f \approx 10^{-8} \mathrm{~cm}^{2}$ the surface area. A common offset current of $10^{-11} \mathrm{~A}$ could thus produce $\mathrm{AgCl}$ at a rate of 300 layers/minute.

Other metals, such as tantalum or tungsten, have also been used to make microelectrodes ${ }^{24,1}$. The hardness of these metals permits making very fine tips which have a relatively large surface area. (The surface ratio of a fine cone to a half sphere is $l / d$ with $l=$ length of cone and $d=$ diameter of half sphere = diameter

24 H. A. Baldwin, S. Frank, and J. Y. Lettrin, Science [Washington] 148, 3676, 1965, 1462. of cone base.) The layer of oxide on these metals causes unfavourable surface properties. $C_{\mathrm{dl}}^{\star}$ is smaller than for bare metal surfaces ${ }^{13}$ and $R_{\mathrm{dl}}^{\star}$ is considerably larger than the observed value of $\mathrm{Ag} / \mathrm{AgCl}{ }^{13,10}$. The mentioned gain in surface area could therefore be negligibly small for ordinary $\mathrm{W}$ or Ta electrodes. Special plating techniques are needed to reduce $R_{\mathrm{dl}}^{*}$ and increase $C_{\mathrm{dl}}^{*}{ }^{5}$

We are indebted to: Prof. Dr. H. Stieve for his continuous support of this investigation, Mr. G. v. SENGBusch for the derivation of eq. (11), Mr. H. SzAmeit for his help with electronics and Deutsche Forschungsgemeinschaft for providing some of the apparatus.

\title{
Some Heterocyclic Nitrogenous Compounds as Radioprotectants for Hematological Levels in X-Irradiated Mice
}

\author{
H. M. Roushdy ${ }^{1}$, T. Pierotti, and M. Polverelli \\ Laboratoire de Radiobiologie, Centre d'Etudes Nucléaires de Grenoble, France \\ (Z. Naturforsch. 25 b, 80-87 [1970]; eingegangen am 5. Mai 1969)
}

\begin{abstract}
In normal controls, the levels of hemoglobin concentration and hematocrit values remained almost unchanged throughout the experimentation period.

Intraperitoneal administration of imidazole and benzimidazole affected rapid pharmacodynamic incidences which were not detected with cysteamine. Administration of imidazole did not induce detectable change in the level of hemoglobin concentration but slightly decreased the hematocrit value. Benzimidazole created slight depression in hemoglobin concentration and exerted no effect on hematocrit value. Cysteamine caused slight depression of both hemoglobin concentration and hematocrit value. Those changes were readily restorable with imidazole and benzimidazole while those with cysteamine lasted for more than three days.

Irradiation caused progressive decrease in hemoglobin concentration and hematocrit values which continued till the death of the animals. A significant increase in the sedimentation rate of red blood cells was recorded.

Irradiation of chemically protected animals caused initial decrease in hemoglobin concentration and hematocrit values which lasted till the fifths post.exposure day. Later, gradual restoration of normal levels of hematological values was recorded. Restoration was more rapid with benzimidazole than with imidazole, while cysteamine lied half way in its action. The increase in sedimentation rate of red blood cells was less pronounced and gradual restoration of the normal sedimentation rate was maintained during the post-irradiation time.

It seems likely that the radioprotectants act on cellular and subcellular levels in the protected tissues but the actual role played by such compounds still awaits further investigation.

Imidazole and benzimidazole proved to be effective radioprotectants of the hematopoietic tissue. Benzimidazole proved to exert the best radioprotective characters amongst the tested compounds in this concern.
\end{abstract}

Since 1949, when the chemical protection against ionizing radiation has been recorded for the first time, excessive studies have been carried out on enormous numbers of chemical compounds that have been suspected to exhibit radioprotective properties (BACQ ${ }^{1 \mathrm{a}}$, TiUnOv et al. ${ }^{2}$, etc.) .

1 Usually working at the Department of Radiobiology, Atomic Energy Establishment, Cairo - U.A.R.

1a Z. M. BACQ, Chemical Protection against Ionizing Radia tions, Charles and Thomas, American Lecture Service, 1965.
In order to give a comprehensive explanation for the phenomenon of chemical radioprotection, repeated investigations have been made to study the chemical structural formation of different radioprotectants and its correlation with their radioprotective properties $\left(\mathrm{BACQ}^{1 \mathrm{a}}\right)$. Moreover, extended

\footnotetext{
${ }^{2}$ L. A. Tiunov et al., Foreign Technology Division, Wright Patterson Air Force Base, Ohio, A.D. 633268 (1966).
} 